\title{
The Relationship between Sluggish Cognitive Tempo, Self-esteem, and Attention-deficit Hyperactivity Disorder among University Students
}

\author{
Shaimaa Ezzat Basha \\ Associate Professor of Psychology, College of Education, \\ Princess Nourah bint Abdulrahman University, Saudi Arabia; \\ Faculty of Arts, Helwan University, Egypt \\ Futiem Nasha Alsubie \\ Assistant Professor of Psychology, College of Education, \\ Princess Nourah bint Abdulrahman University; \\ Umm Al-Qura University, Saudi Arabia
}

DOI: https://doi.org/10.36941/jesr-2021-0043

\section{Abstract}

The present paper aims at determining the contribution of the Sluggish Cognitive Tempo (SCT) and self-esteem to predicting Attention-Deficit Hyperactivity Disorder (ADHD) among female university students in Saudi Arabia. It examines the differences in the research variables according to academic achievement. It also identifies the correlations of these variables. The authors applied the research instruments, i.e., the Adult ADHD Self-Report Scale (ASRS-v1.1), Adult Concentration Inventory (ACI), and Rosenberg's Self-Esteem Scale (RSES) to a sample of 203 female university students aged 19-31 years $(M=23.29$ years; $S D=3.74$ years $)$. The results showed no differences in the mean scores of ASRS, ACI, and negative self-esteem in the achievement levels among university students. In contrast, there was a positive direct relationship between ADHD, SCT, and negative self-esteem. SCT contributed significantly (by $40 \%$ ), whereas self-esteem contributed by $6 \%$ in predicting ADHD among university students. The study highlighted the contribution of both negative selfesteem and SCT to predicting ADHD among Saudi university students to understand the nature of the disorder and its predictors. The findings of this study can be utilized to develop preventive programs for enhancing selfesteem and increasing attention among university students.

Keywords: Attention Deficit Hyperactivity Disorder (ADHD), Sluggish Cognitive Tempo (STC), Self-esteem, Academic achievement

\section{Introduction}

The present research paper aims at determining the contribution of SCT and self-esteem to predicting ADHD among female university students in Saudi Arabia. It examines the differences in the research variables according to academic achievement. It also explores the correlations of these variables. The topic under study is one of the preventive topics of psychopathology.

ADHD is a relatively recent diagnostic concept. It is used to describe children, adolescents, and 
adults with a set of combined symptoms of attention deficit, absent-mindedness, impulsivity, hastiness, and hyperactivity (Abd Alsadek, 2009). ADHD symptoms are linked to dysfunction in a variety of life domains both for children and adults. Moreover, ADHD persists to the age of 25 in 15$60 \%$ of children with ADHD with a prevalence rate of about $2.5 \%$ (Voinescu, Szentagotai, and David, 2012).

Since it is considered a persistent neurobiological disorder, the characteristics of ADHD persist and almost $4.4 \%$ of adults in the USA exhibit symptoms that yield ADHD diagnosis (Combs, Canu, Fulks, and Nieman, 2014). Gaub and Carlson (1997) show that girls with ADHD may have a greater cognitive and verbal impairment than boys with ADHD. Additionally, there are no gender differences in impulsivity and academic performance.

Gibbins, Toplak, Flora, Weiss, and Tannock (2012) suggest that one general factor exists for ADHD symptoms. The replication of the general factor suggests that it continues from childhood through adulthood. Garner et al. (2017) report that SCT symptoms are distinct and separate from ADHD symptoms.

In this regard, about $30-50 \%$ of the youth with ADHD have slow processing, sluggishness, and irregular alertness (SCT) (Langberg, Becker, Dvorsky, and Luebbe, 2014b). Lahey et al. showed in the 1980 s for the first time that SCT symptoms differ from ADHD symptoms (as cited in Langberg et al., 2014b). Moreover, Hinshaw (2002) points out that more examination of psychopathological processes and competencies among girls with ADHD is needed. This issue supports the need for conducting more research on female university students.

Marshall, Evans, Eiraldi, Becker, and Power (2014) note that the literature ignores using SCT symptoms in identifying youth with ADHD-Hyperactivity/impulsivity (ADHD-HI) subgroup. Becker et al. (2018) point out that SCT is uniquely correlated with poorer social-emotional adjustment. They emphasize the need to replicate these studies in a population of young adults and expand them to other domains of social-emotional functioning (e.g., self-esteem) to fully understand the impact of SCT on adjustment. Therefore, the present study aims at identifying the contribution of SCT to predicting selfesteem. ADHD can be caused by many factors, some of them are related to the brain, others may be genetic, environmental, or nutritional (Ahmed \& Badr, 1999).

The relevance of studying ADHD among female university students is not only due to its high prevalence rates, but also because of its adverse effects on their personal, academic, and professional life. ADHD predicts several latent problems of the various development stages, including criminal behavior resulting from impulsivity, poor self-esteem, deficiency in dealing with frustrating situations, difficulties in controlling anger, difficulties in monitoring and regulation of personal actions, as if their brain is a computer hit with a virus (Abd Alsadek, 2009). The SCT scale also predicts homework problems as the only SCT variable predicting school grades above and beyond ADHD symptoms and relevant common variables (Langberg, Becker, and Dvorsky, 2014a). Moreover, it is also found that undergraduate students with ADHD exhibit more difficulties in motivation and information processing compared to their non-ADHD peers (Combs et al., 2014).

The importance of the present study is related to the examined variables, as shown below. Its theoretical importance is shown in the framework of studies that examine ADHD. The prevalence rate of ADHD after the secondary educational stage is estimated between 2-8\% (Gray, Woltering, Mawjee, and Tannock, 2014). Furthermore, ADHD symptoms can continue through adulthood, which has a great impact on personal integrity, personal relationships, and career. Many individuals with ADHD do not receive the appropriate treatment, partially due to the difficulties in diagnosis especially in adults (Kessler et al., 2005).

The literature reports an increase in the prevalence rates of ADHD and continuity through adulthood. There is a lack of interest in Arab environments in studying ADHD. Therefore, identifying the nature of this disorder among female university students is not only important but also necessary as they constitute a vital sector receiving development efforts in Saudi Arabia within the framework of the empowerment of women in society. The comorbidity of ADHD and SCT is associated with higher impairment in social, academic, and executive functioning among the youth with ADHD (Langberg et 
al., 2014b).

The present study also investigates self-esteem because it is a primary and inherent concept in life events and the feeling of self throughout time. Individuals need to develop self-esteem as it allows them to give personal worth to themselves, feel trustworthy, and worthy of (Mcnamara, 200o). From an applied perspective, the importance of this research is due to examining ADHD and its relationship to self-esteem and SCT among female university students, which helps in the development of counseling programs or practical proposals that help limit its adverse effects on their academic achievement and psychological well-being.

According to Abd Alsadek (2009), ADHD symptoms include difficulty in maintaining attention and focus to perform tasks, inability to learn new skills requiring mental concentration, difficulty in stability or continuity of performing activities, and impulsivity in conversation. Abd Alsadek adds that they include the tendency to interrupt others' speech, failure to fully consider the consequences due to the speed of decision making, and failure to maintain social relationships. SCT is defined as "inconsistent alertness and orientation such as sluggishness, daydreaming, drowsiness, lethargy, and hypoactivity" (Watabe, Owens, Evans, and Brandt, 2014, p. 105).

Rosenberg defines self-esteem as "one's positive or negative attitude toward oneself and one's evaluation of one's own thoughts and feelings overall in relation to oneself." That is, high self-esteem means that the individual considers him/herself worthy and important, whereas low self-esteem means one's lack of satisfaction with oneself or self-rejection and loathing (as cited in Saleh, 1992). Thus, selfesteem is an evaluating dimension in a complex network of self-related cognitive constructs, such as attitudes and beliefs, and overall constitute the concept of self which is contrary to the descriptive components of the concept of self, including evaluating beliefs related to oneself in terms of body features, abilities, psychological characteristics, and self-value (Salama, 1991).

\section{Questions}

The present research problem can be outlined in the following questions:

1. How much do ADHD symptoms, self-esteem, and SCT vary according to academic achievement?

2. What are the magnitude and correlation of the ADHD symptoms, self-esteem, and SCT among female university students?

3. To what extent does self-esteem contribute to predicting ADHD symptoms among university students?

4. To what extent does self-esteem SCT contribute to predicting ADHD symptoms among university students?

The present study mainly aims at determining the contribution of SCT and self-esteem to predicting ADHD symptoms scores among female university students. It examines the differences in the research variables according to academic achievement. It also explores the correlation between these variables.

The study has other measurement-related goals that it seeks to achieve, including the preparation of an Arabic version of new instruments to measure the relevant research variables, namely:

a. Arabization of the ADHD measurement instrument and determining its psychometric characteristics in the Saudi environment among female university students.

b. Arabization of the SCT measurement instrument and determining its psychometric characteristics in the Saudi environment among female university students.

\section{Materials and Methods}

The present study aims at identifying the predictive ability of self-esteem and SCT of ADHD among female university students, finding the differences in these variables according to academic achievement, and identifying the correlation between these variables. Therefore, the correlative and 
differential descriptive method was deemed the most appropriate method to the nature and objectives of this study, as well as the appropriate method for testing and verifying the hypotheses. This method quantitatively describes the measured phenomenon by determining the degree of association between the variables.

\subsection{Sampling}

The final research sample consisted of 203 female university students in Riyadh aged 19-31 years (M= 23.39, SD=3.74 years) at the Colleges of Education, Sciences, Arts, Home Economics, Business Administration, and Shari'a. Tables 1 and 2 demonstrate the demographic properties of the research sample.

Table 1: Distribution of participants according to college

\begin{tabular}{|l|c|c|}
\hline \multirow{2}{*}{ College } & \multicolumn{2}{|c|}{ Sample } \\
\cline { 2 - 3 } & $\mathrm{N}$ & $\%$ \\
\hline Arts & 10 & 4.93 \\
\hline Education & 135 & 66.50 \\
\hline Home Economics & 3 & 1.48 \\
\hline Business Administration & 33 & 16.26 \\
\hline Science & 15 & 7.39 \\
\hline Computer Science & 3 & 1.48 \\
\hline Shari'a & 4 & 1.96 \\
\hline Total & 203 & 100 \\
\hline
\end{tabular}

Table 2: Distribution of participants according to academic achievement

\begin{tabular}{|l|c|c|}
\hline \multirow{2}{*}{ Academic achievement } & \multicolumn{2}{|c|}{ Sample } \\
\cline { 2 - 3 } & $\mathrm{N}$ & $\%$ \\
\hline Low achievers & 35 & 17.2 \\
\hline Medium achievers & 84 & 41.4 \\
\hline High achievers & 84 & 41.4 \\
\hline Total & 203 & 100 \\
\hline
\end{tabular}

\subsection{Instruments}

To validate the research instruments, it was applied to a sample of 154 female university students in Riyadh aged 19-38 years $(M=22.77$; $S D=3.29)$. The data from this sample were used to verify the validity and reliability of the present research instruments.

\subsection{Adult ADHD self-report scale (ASRS-v1.1)}

This scale was developed in 2012 by Adler et al and localized for the Saudi setting. It is an 18-item ADHD self-report scale, easy to use, reliable, and cost-effective method for gathering information about current ADHD symptoms. It was developed for adults and a symptom checklist in cooperation with the World Health Organization. It is based on a five-point Likert from zero (never) to four (too often).

As to examining the psychometric properties of the scale in the foreign setting, the test-retest reliability was calculated $(\mathrm{r}=.66)$, and a moderate to good fit was found between the reports of the symptom checklist of the ASRS and parallel reports $(\mathrm{r}=.47)$ on a sample of 135 university students (Mean age $=24 ; 42 \%$ males) (Gray et al., 2014). To localize the scale for the Saudi setting, the ASRS was translated into Arabic, and the appropriateness of items to the Saudi environment was taken into 
account during the translation process. The authors did not make any modification (by adding or deleting items) in the number or content of items, thus ending with the original 18 -item form. The response choices were modified, however, from (never) to (too often).

In the present study, the following psychometric properties of the final revised version of the ASRS were checked:

- Internal consistency: The correlation between the item score and the total score after subtracting the item score was calculated. The correlation coefficients between the item score and the total score ranged between 0.36 and 0.68 , which are acceptable values. Therefore, the authors did not eliminate any items.

- Cronbach's Alpha: The Cronbach's Alpha reliability coefficient of the full scale was calculated. The Cronbach's Alpha was o.81, indicating that all items measure the same content.

- Factor validity: Factor analysis was conducted by Hotelling's basic components method using SPSS software, and relying on Kaiser normalization criterion set by Guttman. Factor analysis of the ASRS 18 items in a sample of 154 participants. After factor rotation using the Oblimin method, the factor analysis of the ASRS items revealed four factors with an Eigenvalue greater than one, accounting for $48.298 \%$ of the total variance. A description of the factors resulting from the factor analysis is detailed below. Table 3 shows the matrix of statistically significant factors and their loadings after orthogonal rotation of factors, as well as the Eigenvalue and correlation variance ratio of each factor.

Table 3: Resulting factors after the rotation of the ASRS items ( $\mathrm{N}=154)$

\begin{tabular}{|c|c|c|c|c|c|}
\hline Items & Factor 1 & Factor 2 & Factor 3 & Factor 4 & Communality \\
\hline 10. & 0.73 & & & & 0.573 \\
\hline 8. & 0.652 & & & & 0.507 \\
\hline 11. & 0.645 & & & & 0.493 \\
\hline 4. & 0.603 & & & & 0.403 \\
\hline 9. & 0.571 & & & & 0.374 \\
\hline 5. & 0.551 & & & & 0.459 \\
\hline 3. & 0.533 & & & & 0.365 \\
\hline 12. & 0.408 & & & & 0.359 \\
\hline 15. & & 0.711 & & & 0.520 \\
\hline 18. & & 0.687 & & & 0.632 \\
\hline 17. & & 0.664 & & & 0.459 \\
\hline 16. & & 0.618 & & & 0.468 \\
\hline 6. & & & 0.690 & & 0.525 \\
\hline 1. & & & 0.520 & & 0.564 \\
\hline 2. & & & 0.309 & & 0.584 \\
\hline 7. & & & & 0.661 & 0.471 \\
\hline 14. & & & & 0.592 & 0.501 \\
\hline 13. & & & & 0.476 & 0.437 \\
\hline Eigenvalue & 4.496 & 1.668 & 1.320 & 1.209 & 8.693 \\
\hline Total variance & 24.980 & 9.267 & 7.336 & 6.716 & 48.298 \\
\hline
\end{tabular}

The factor analysis revealed four factors after factor rotation by the Oblimin method. The Eigenvalue of each of these factors was greater than one, and they accounted for more than $48.298 \%$ of the total correlation variance. These factors are, as follows:

- Factor 1: This factor constituted $24.980 \%$ of the total correlation variance. Its Eigenvalue was 4.496. Eight items essentially loaded on this factor (i.e., 10, 8, 11, 4, 9, 5, 3, and 12). The items contain entries with loadings ranging from 0.733 to 0.408 . The content of this factor entitled "Distraction and Concentration Difficulty" involves distraction, fidgeting, difficulty to concentrate, and difficulty to maintain attention (e.g., "how often do you misplace or have 
difficulty finding things at home or work?").

- Factor 2: This factor constituted $9.267 \%$ of total correlation variance, with an Eigenvalue of 1.668. Four items were essentially loaded on this factor (i.e., 15, 18, 17, and 16). These items contain entries with loadings ranging from 0.711 to 0.618 . The content of this factor entitled "Talking too much" involves talking too much, interrupting others, difficulty in waiting for one's turn (e.g., "How often do you find yourself talking too much when you are in social situations?").

- Factor 3: This factor constituted $7.336 \%$ of the total correlation variance, with an Eigenvalue of 1.320. Three items were essentially loaded on this factor (i.e., 6, 1, and 2). These items contain entries with loadings ranging from 0.690 to 0.309 . The content of this factor entitled "hyperactivity" involves difficulty in completing details, difficulty in organizing objects, and being overactive (e.g., "how often do you feel overly active and compelled to do things, like you were driven by a motor?").

- Factor 4: This factor constituted $6.716 \%$ of the total correlation variance, with an Eigenvalue of 1.209. Three items were essentially loaded on this factor (i.e., 7, 14, and 13). These items contain entries with loadings ranging from 0.661 to 0.476 . The content of this factor entitled "difficulty to relax" involves careless or simple mistakes, feeling restless, fidgeting, and difficulty in relaxing (e.g., "how often do you make careless mistakes when you have to work on a boring or difficult project?").

By calculating factor validity, it was shown that all items of the scale were loaded on all the factors in the correlation matrix. Thus, the final number of items in the ASRS revised version was 18 objects at the factor analysis level. The factor structure of the scale shows content validity, consistency of its items, and efficiency in measuring what it aims to measure. Consequently, after checking the psychometric properties of the ASRS, it was found valid for use.

The final version of the ASRS consisted of 18 items. It was scored by scoring the response selected by respondents from five choices (too often $=5$, Often $=5$, Sometimes $=3$, Rarely $=2$, Never $=1$ ). The scale's total score ranges from 18 to 90 points. The higher score indicates a greater negative aspect and higher ADHD.

\subsection{Adult Concentration Inventory (ACI)}

The ACI was originally developed by Becker et al. (2018) and localized for the Saudi setting. It is a selfreport scale to evaluate SCT in adults. The ACI contained 13 items that were determined by a recent meta-analysis as optimal for distinguishing between SCT and ADHD. Moreover, the authors added three items about mental confusion, as preliminary evidence found these items are important in assessing SCT. The ACI consisted of 16 items of SCT symptoms. It is based on a three-point Likert scale (zero $=$ never applies, $\mathbf{1}=$ sometimes applies, $\mathbf{2}=$ always applies) with respect to the previous six months. The validity and reliability of the ACI were calculated in a sample of 3172 university students (both males and females) aged $18-29(\mathrm{M}=19.24 ; \mathrm{SD}=1.52)$. The $\mathrm{ACI}$ reliability in the original version was calculated using Cronbach's Alpha that scored .89.

The ACI was translated into Arabic, and the appropriateness of the items to the Saudi environment was considered. The response alternatives were modified to be (always applies $=3$ and never applies $=1$ ). In the present study, the following psychometric properties of the ACI revised version were checked.

- Internal consistency: To find the internal consistency the correlation between the item score and the ACI total score after subtracting the item score was calculated. The correlation coefficients between the item score and the total score ranged from 0.53 and 0.74 , which are acceptable values. Therefore, no items were eliminated.

- Cronbach's Alpha: Cronbach's Alpha of the full scale was calculated and scored o.88, which indicated that all the items in the scale measure the same content.

- Factor validity: Factor analysis was conducted by Hotelling's basic components method using 
SPSS software, and relying on Kaiser normalization criterion set by Guttman. Factor analysis of the ACI's 16 items was done on a sample of 154 participants. After factor rotation using the Oblimin method, the factor analysis of the ACI items revealed three factors with an Eigenvalue greater than one, accounting for $49.820 \%$ of the total variance. A description of the factors resulting from the factor analysis is detailed below. Table 4 shows the matrix of statistically significant factors and their loadings after orthogonal rotation of factors, as well as the Eigenvalue and correlation variance ratio of each factor.

Table 4: Resulting factors after rotation of the ACI items $(\mathrm{N}=154)$

\begin{tabular}{|c|c|c|c|c|}
\hline Items & Factor 1 & Factor 2 & Factor 3 & Communality \\
\hline 14. & 0.671 & & & 0.564 \\
\hline 8. & 0.648 & & & 0.492 \\
\hline 9. & 0.638 & & & 0.429 \\
\hline 1. & 0.573 & & & 0.456 \\
\hline 11. & 0.484 & & & 0.357 \\
\hline 5. & 0.388 & & & 0.366 \\
\hline 2. & & 0.708 & & 0.525 \\
\hline 12. & & 0.692 & & 0.677 \\
\hline 13. & & 0.650 & & 0.674 \\
\hline 10. & & 0.580 & & 0.603 \\
\hline 3. & & 0.547 & & 0.471 \\
\hline 7. & & 0.403 & & 0.395 \\
\hline 15. & & & & 0.401 \\
\hline 4. & & & & 0.730 \\
\hline 16. & 5.761 & 1.176 & 1.035 & 0.584 \\
\hline 6. & 36.003 & 7.350 & 6.466 & 7.972 \\
\hline Eigenvalue & & & & \\
\hline Total variance & & & & \\
\hline
\end{tabular}

The factor analysis found three factors after theme rotation by the Oblimin method. The Eigenvalue of each factor was greater than one, and they accounted for $49.820 \%$ of the total correlation variance. A detailed description of these factors is as follows:

- Factor 1: This factor accounted for $36.003 \%$ of the total correlation variance. Its Eigenvalue was 5.761. Six items were essentially loaded on this factor (i.e., 14, 8, 9, 1, 11, and 5). These items include entries with loadings ranging from 0.671 and 0.388 . The content of this factor entitled "slow thinking and action" involves slow thinking and action, getting tired easily, forgetfulness, and lack of motivation (e.g., "My thinking seems slow or slowed down").

- Factor 2: This factor accounted for $7.350 \%$ of the total correlation variance, and its Eigenvalue was 1.176. Seven items essentially loaded on this factor (i.e., 2, 12, 13, 10, 3, 7, and 15). These items included entries with loadings ranging from 0.708 and 0.403 . The content of this factor entitled "absent-mindedness and distracting thoughts" involves mind fog, absentmindedness, distracting thoughts, confusion, disorientation, and daydreaming (e.g., "My mind feels like it is in a fog").

- Factor 3: This factor accounted for $6.466 \%$ of the total correlation variance, with an Eigenvalue of 1.035. Three items were essentially loaded on it (i.e., 4, 16, and 6). These items included entries with loadings ranging from 0.730 to 0.597 . The content of this factor entitled "lack of energy" involves drowsiness during the day, lack of activity, and difficulty in putting ideas in the form of words.

It was found that all the ACI items were loaded on the factors of the correlation matrix by calculating factor validity. Thus, the number of ACI-revised version's items was 16 at the factor analysis level. The factor structure of the ACI indicated its content validity, item consistency, and efficiency in 
measuring what it aims to measure. Thus, after checking the psychometric properties of the ACI, it was found valid for use.

The final version of the ACI consisted of 16 items. Scoring is done by scoring each item according to the respondent's selected response from three response alternatives (always applies $=3$, sometimes applies $=2$, and never applies $=1$ ). The total ACI score ranges from 16 to 48 points. The higher score demonstrates the negative aspect and greater SCT.

\subsection{Rosenberg's Self-Esteem Scale (RSES)}

The RSES was translated into Arabic by Salama (1991). This instrument provides a quantitative estimation of one's self-esteem in general. It consists of 10 items, the respondent determines how applicable these items are to him/herself based on four levels. The score of each item ranges from one to four points, and the total RSES score ranges from 10 to 40 points. The RSES items can be inversely scored. Thus, the score reflects a negative self-evaluation, view of deficits, weaknesses, and failures. All the items can also be positively scored so that the score reflects positive self-esteem.

Salama (1991) checked the psychometric properties of the RSES by calculating its validity and reliability in a sample of 97 male and female students at the Faculty of Arts, Zagazig University (50 males, 47 females) aged $18-25(M=21.2$ years; $S D=2.1)$. Reliability was calculated by determining the Cronbach's Alpha coefficient of the data, and it was .86. The concurrent validity of the RSES was calculated with other self-esteem instruments. The correlation coefficient of the RSES score and Cooper-Smith Scale score was -o.66 (as the RSES score reflects negative self-esteem, whereas the score of the used criterion reflects positive self-esteem). Moreover, the correlation coefficient between the RSES scores and the scores of self-evaluations scale, a subscale in the Personality Questionnaire is $(\mathrm{r}=$ o.72). The RSES scores correlate with Beck's Depression Inventory in a sample of depressed individuals $(\mathrm{N}=50)(\mathrm{r}=0.78)$. It is noteworthy that depressed individuals are known for their low self-esteem. A depressed individual can be considered the other extreme of a person with high self-esteem.

In the present study, the reliability of the RSES was checked using Chronbach's Alpha. The Alpha coefficient of the full scale was o.8o (a high-reliability coefficient), indicating that the scale's items are homogenous and express the same content. Appropriate statistical techniques were used to answer the research questions (e.g., mean, standard deviation, variance analysis, correlation coefficient, and regression analysis).

\section{Results and Discussion}

\subsection{Statistical Analysis}

Relevant statistical analysis methods were used to answer the research questions (e.g. mean, standard deviation, analysis of variance, correlation coefficients, and regression analysis). Table 5 shows the means, standard deviations, skewness coefficients of the research variables among female university students.

Table 5: Mean, SD, Skewness of research variables in female university students

\begin{tabular}{|c|c|c|c|c|c|c|c|}
\hline Scales & Statistical indicators & SD & Skewness & $\begin{array}{c}\text { Sample's } \\
\text { Maximum } \\
\text { score }\end{array}$ & $\begin{array}{c}\text { Sample's } \\
\text { Minimum } \\
\text { score }\end{array}$ & $\begin{array}{c}\text { Highest } \\
\text { Possible } \\
\text { score }\end{array}$ & $\begin{array}{c}\text { Lowest } \\
\text { Possible } \\
\text { score }\end{array}$ \\
\hline ADHD & 9.89 & 44.773 & -0.200 & 71 & 18 & 90 & 18 \\
\hline ACI & 6.64 & $\mathbf{2 7 . 3 1 5}$ & 0.288 & 44 & 16 & 48 & 16 \\
\hline Negative self-esteem & 4.92 & 15.862 & 1.112 & 36 & 10 & 40 & 10 \\
\hline
\end{tabular}

A value equal to or greater than 2.58 indicates skewness. 


\subsection{Results}

Hypothesis 1: "there are statistically significant differences in the different achievement levels on the ADHD, SCT, and self-esteem among university students". One-way analysis of variance $(1 \times 3)$ was used to determine the differences in the ASRS, ACI (SCT), and RSES mean scores according to academic achievement. Table 6 shows the findings of this procedure.

Table 6: Differences in the ASRS, ACI (SCT), and RSES mean scores according to academic achievement $(\mathrm{N}=203)$

\begin{tabular}{|c|c|c|c|c|c|c|}
\hline \multicolumn{7}{|l|}{ ANOVA } \\
\hline & & Sum of Squares & Df & Mean Square & $\mathrm{F}$ & Sig. \\
\hline \multirow{3}{*}{ ADHD } & Between Groups & 1.230 & 2 & .615 & .006 & .994 \\
\hline & Within Groups & 18991.765 & 197 & 96.405 & & \\
\hline & Total & 18992.995 & 199 & & & \\
\hline \multirow{3}{*}{ SCT } & Between Groups & 85.184 & 2 & 42.592 & .982 & .376 \\
\hline & Within Groups & 8546.211 & 197 & 43.382 & & \\
\hline & Total & 8631.395 & 199 & & & \\
\hline \multirow{3}{*}{ Self-esteem } & Between Groups & 83.042 & 2 & 41.521 & 1.731 & .180 \\
\hline & Within Groups & 4725.113 & 197 & 23.985 & & \\
\hline & Total & 4808.155 & 199 & & & \\
\hline
\end{tabular}

Table (6) shows no differences between the different achievement levels in the ASRS, ACI (SCT), RSES mean scores of the research sample.

Hypothesis 2: "there is a positive significant correlation between ADHD scores and both selfesteem and SCT scores among university students". Table (7) shows the correlation coefficients between the research variables.

Table 7: Correlation coefficients of the ADHD symptoms, SCT, and self-esteem $(\mathrm{N}=\mathbf{2 0 3})$

\begin{tabular}{|l|c|c|c|}
\hline \multicolumn{5}{|l|}{ Correlations } \\
\hline & ADHD & SCT & Self-esteem \\
\hline ADHD & 1 & $.633^{* *}$ & $.247^{* *}$ \\
\hline SCT & $.633^{* *}$ & 1 & $.323^{* *}$ \\
\hline Negative Self- Esteem & $.247^{* *}$ & $.323^{* *}$ & 1 \\
\hline
\end{tabular}

Sig. (2-tailed), ${ }^{* *}, 000$

Table 7 shows significant positive correlation coefficients between ADHD and both SCT and negative self-esteem $(\mathrm{p}=\mathrm{o.001})$. It also shows significant positive correlation coefficients between SCT and negative self-esteem $(\mathrm{p}=0.001)$.

Hypothesis 3: "self-esteem significantly contributes to predicting ADHD among university students". To test this hypothesis, a simple linear regression analysis was done to calculate the contribution of self-esteem to predicting ADHD among university students.

Table 8: Simple linear regression analysis of predicting the ADHD level among university students

\begin{tabular}{|c|c|c|c|c|c|c|c|c|c|}
\hline $\begin{array}{c}\text { Dependent } \\
\text { Variable }\end{array}$ & $\begin{array}{c}\text { Independent } \\
\text { variable }\end{array}$ & Contribution & B & $\begin{array}{c}\text { Standardized } \\
\text { Coefficient Beta }\end{array}$ & $\begin{array}{c}\text { Fixed } \\
\text { value }\end{array}$ & F & Sig. & T & Sig. \\
\hline ADHD (N = 203) & Negative self-esteem & 0.061 & 0.497 & 0.247 & 36.886 & 13.096 & 0.000 & 3.619 & 0.000 \\
\hline
\end{tabular}

Table 8 shows that negative self-esteem predicted 6.1\% of the variance in ADHD manifestations among university students. This finding indicates that elevated self-esteem levels in students increase the 
likelihood of suffering ADHD.

Hypothesis 4: "SCT significantly contributes to predicting ADHD among university students". To test this hypothesis, simple linear regression was used to calculate the SCT contribution to predicting ADHD among university students.

Table 9: Simple linear regression analysis of predicting the ADHD level among university students

\begin{tabular}{|c|c|c|c|c|c|c|c|c|c|}
\hline $\begin{array}{c}\text { Dependent } \\
\text { Variable }\end{array}$ & $\begin{array}{c}\text { Independent } \\
\text { variable }\end{array}$ & Contribution & B & $\begin{array}{c}\text { Standardized } \\
\text { Coefficient Beta }\end{array}$ & $\begin{array}{c}\text { Fixed } \\
\text { value }\end{array}$ & F & Sig. & T & Sig. \\
\hline ADHD (N = 203) & SCT & 0.400 & $\mathbf{0 . 9 4 3}$ & 0.633 & $\mathbf{1 9 . 0 2 7}$ & $\mathbf{1 3 4 . 2 2 4}$ & $\mathbf{0 . 0 0 0}$ & $\mathbf{1 1 . 5 8 6}$ & $\mathbf{0 . 0 0 0}$ \\
\hline
\end{tabular}

Table 9 shows that SCT contributes $40 \%$ of the variance in ADHD manifestations among university students. This finding indicates that higher levels of SCT in students increase the likelihood of suffering ADHD.

\section{Discussion}

Concerning hypothesis 1, table 6 shows no differences according to the different achievement levels in the ASRS, ACI (SCT), and self-esteem mean scores. This finding means that female university students having different achievement levels do not differ in ADHD, SCT, and self-esteem. This can be explained by the fact that students with ADHD and SCT (students with comorbidity of the two conditions) had significantly more impairment in school maladjustment compared to students with ADHD only (Langberg et al., 2014b). Both Comorbidity with ADHD and SCT may lead to greater low academic achievement among students. Additionally, inattention symptoms, not hyperactivity/impulsivity, had a greater share in the impairment of key domains, such as neuropsychological and academic functioning (Bauermeister, Barkley, Bauermeister, Martínez, and McBurnett, 2012).

The findings of this study are consistent with the findings of Carlson and Mann (2002) that compared children with ADHD to children scoring high on the SCT scale and previous comparisons with the ADHD subtypes and found no differences between the two groups in the attention level or learning problems. However, it differs from the findings of Hinshaw (2002) that girls with ADHD exhibited dysfunction in academic and cognitive functioning. It also differs from the findings of Lee, Burns, Snell, and McBurnett (2014) and Willcutt et al. (2014) that found a correlation between the higher scores on the SCT scale and the lower levels of academic and social competence.

Concerning hypothesis 2, table 7 shows a significant positive correlation between ADHD levels and both SCT and negative self-esteem. There is also a significant positive correlation between SCT and negative self-esteem. That is, the higher ADHD symptoms are, the higher SCT and negative selfesteem become. The significant positive correlation between ADHD levels and SCT may be explained in the light of the findings of Barkley (2013) that SCT is a distinct disorder from ADHD, but both may coexist in $39-59 \%$ of the cases of either disorder. This finding is consistent with the findings of Bauermeister et al. (2012) and Hartman, Willcutt, Rhee, and Pennington (2004) that found a correlation between ADHD symptoms and SCT among children.

Moreover, SCT estimations showed significant correlations in samples of students with and without ADHD (Garner, Marceaux, Mrug, Patterson, and Hodgens, 2010; Kirbekk, Hansen, Oerbeck, and Kristensen, 2011; Langberg et al., 2014b). Meanwhile, the negative emotional climate enhanced SCT associations with ADHD and depression symptoms (Fredrick et al., 2019). Furthermore, the SCT symptoms were found to significantly correlate with low self-esteem and academic difficulties. It was suggested that SCT may be a psychological disorder on its own (Becker et al., 2018). Negative selfesteem was also associated with feelings of incompetence and mental health problems, whereas positive self-esteem leads to good adjustment and internal regulation (Mruk, 1999).

Concerning hypotheses 3 and 4, tables 8-9 show that SCT contributed significantly (by 40\%) and self-esteem contributed significantly (by 6.1\%) to predicting ADHD among university students. This 
result is consistent with the findings related to hypothesis 2 that there is a significant correlation (o.63) between SCT and ADHD, and a significant correlation (0.25) can be found between self-esteem and ADHD. It is also consistent with the findings that mediation follow-up analyses revealed that SCT may at least partially explain the heterogeneity in ADHD (Kamradt Momany, and Nikolas, 2018). The higher levels of SCT also predicted higher levels of anxiety, depression, academic, and social weakness (Bernad, Servera, Becker, and Burns, 2016). Moreover, it is consistent with Cook, Knight, Hume, and Qureshi (2014) that ADHD is associated with low self-esteem during childhood.

In short, the results of the present study answered its main questions. The statistical analyses revealed the significant contribution of negative self-esteem and SCT to predicting ADHD. The study also found a positive correlation between ADHD, SCT, and negative self-esteem, and between SCT and negative self-esteem.

\section{Conclusion}

Based on the research findings, the authors make the following recommendations:

a. The relationship between SCT, executive functions, and interpersonal problems should be investigated.

b. Self-esteem should be studied as a moderator of the relationship between ADHD and interpersonal problems.

The theoretical and applied relevance of the study can be summarized as follows:

- The contribution of both negative self-esteem and SCT to predicting ADHD among university students in Saudi Arabia was determined, in an attempt to understand the nature of this disorder, its predictors, evaluation methods, and intervention strategies.

- The results of the present study can be utilized in developing preventive programs to enhance self-esteem and increase attention among university students.

- The measures used in this study can be used in screening, diagnosis, and prediction, as well as in research and following up the results of psychotherapy, rehabilitation, and preventive programs.

\section{Acknowledgement}

This research was funded by the Deanship of Scientific Research at Princess Nourah bint Abdulrahman University through the Fast-Track Research Funding Program.

References

Abd Alsadek, F. (2009). Symptoms of attention disturbance and hyperactivity and its relationship to emotional intelligence among university students (in Arabic). Annals of the Center for Research and Psychological Studies-Cairo University, 10(5), 1-70.

Adler, L., Shaw, D., Spencer, T., Newcorn, J., Hammerness, P., Sitt, D., ... \& Faraone, S. (2012). Preliminary examination of the reliability and concurrent validity of the attention-deficit/hyperactivity disorder selfreport scale v1.1 symptom checklist to rate symptoms of attention-deficit/hyperactivity disorder in adolescents. Journal of Child and Adolescent Psychopharmacology, 22(3), 238-244.

Ahmed, A. \& Badr, F. (1999). Attention disorder in children causes, diagnosis and treatment (in Arabic) ( ${ }^{\text {st }}$ ed.). Egypt: Egyptian Renaissance Library.

Bauermeister, J., Barkley, R., Bauermeister, A., Martínez, J., \& McBurnett, K. (2012). Validity of the sluggish cognitive tempo, inattention, and hyperactivity symptom dimensions: neuropsychological and psychosocial correlates. Journal of Abnormal Child Psychology, 40(1), 683-697. doi:https://doi.org/10.1007/s10802-011-9602-7

Becker, S., Burns, G., Garner, A., Jarrett, M., Luebbe, A., Epstein, J., \& Willcutt, E. (2018). Sluggish cognitive tempo in adults: Psychometric validation of the Adult Concentration Inventory. Psychological Assessment, 3o(3), 296-310. 
Bernad, M., Servera, M., Becker, S., \& Burns, L. (2016). Sluggish cognitive tempo and ADHD inattention as predictors of externalizing, internalizing, and impairment domains: A 2-year longitudinal study. Journal of Abnormal Child Psychology, 44(1), 771-785, https://doi.org/10.1007/s10802-015-0o66-z.

Carlson, C. \& Mann, M. (2002). Sluggish cognitive tempo predicts a different pattern of impairment in the attention deficit hyperactivity disorder, predominantly inattentive type. Journal of Clinical Child E Adolescent Psychology, 31(1), 123-129.

Combs, M., Canu, W., Fulks, J., \& Nieman, D. (2014). Impact of sluggish cognitive tempo and attentiondeficit/hyperactivity disorder symptoms on adults' quality of life. Applied Research in Quality ofLife, 9(4), 981995 .

Cook, J., Knight, E., Hume, I. \& Qureshi, A. (2014). The self-esteem of adults diagnosed with attentiondeficit/hyperactivity disorder (ADHD): A systematic review of the literature. ADHD Attention Deficit and Hyperactivity Disorders, 6(1), 249-268. https://doi.org/10.1007/s12402-014-0133-2.

Fredrick, J., Luebbe, A., Mancini, K., Burns, L., Epstein, J., Garner, A., ... \& Becker, S. (2019). Family environment moderates the relation of sluggish cognitive tempo to attention-deficit/hyperactivity disorder inattention and depression. Journal of Clinical Psychology, 75(1), 221-237.

Garner, A., Peugh, J., Becker, S., Kingery, K., Tamm, L., Vaughn, A., ... \& Jeffery, N. (2017). Does Sluggish Cognitive Tempo fit within a bi-factor model of ADHD? Journal of Attention Disorders, 21(8), $642-654$. https://doi.org/10.1177\%2F1087054714539995.

Garner, A., Marceaux, J., Mrug, S., Patterson, C. \& Hodgens, B. (2010). Dimensions and correlates of attentiondeficit/hyperactivity disorder and sluggish cognitive tempo. Journal of Abnormal Child Psychology, 38(1), 10971107.

Gaub, M. \& Carlson, C. (1997). Gender differences in ADHD: A meta-analysis and critical review. Journal of the American Academy of Child E Adolescent Psychiatry, 36(8), 1036-1045. doi:https://doi.org/10.1097/o0oo4583199708000-0oo11.

Gibbins, C., Toplak, M., Flora, D., Weiss, D., \& Tannock, R. (2012). Evidence for a general factor model of ADHD in adults. Journal of Attention Disorders, 16(8), 635-44. doi: 10.1177/1087054711416310.

Gray, S., Woltering, S., Mawjee, K., \& Tannock, R. (2014). The adult ADHD self-report scale. Peer Journal, 2 (3), e324. doi:PeerJ, DOI 10.7717/peerj.324.

Hartman, C., Willcutt, E., Rhee, S., \& Pennington, B. (2004). The relation between sluggish cognitive tempo and DSM-IV ADHD. Journal of Abnormal Child Psychology, 32(1), 491-503.

Hinshaw, S. (2002). Preadolescent girls with attention-deficit/hyperactivity disorder: I. Background characteristics, comorbidity, cognitive and social functioning, and parenting practices. Journal of Consulting and Clinical Psychology, 7o(5), 1086-1098.

Kamradt, J., Momany, A. \& Nikolas, M. (2018). Sluggish cognitive tempo symptoms contribute to heterogeneity in adult attention-deficit hyperactivity disorder. Journal of Psychopathology and Behavioral Assessment, 40(2), 206-223. https://doi.org/10.1007/s10862-017-9631-9.

Kessler, R., Adler, L., Ames, M., Demler, O., Faraone, S., Hiripi, E., ... \& Walters, E. (2005). The World Health Organization Adult ADHD Self-Report Scale (ASRS): a short screening scale for use in the general population. Psychological Medicine, 35(2), 245-256.

Kirbekk, B., Hansen, B.H., Oerbeck, B., \& Kristensen, H. (2011). The relationship between sluggish cognitive tempo, subtypes of attention-deficit/hyperactivity disorder, and anxiety disorders. Journal of Abnormal Child Psychology, 39(1), 513-525.

Langberg, J., Becker, S., Dvorsky, M. (2014a). The association between Sluggish Cognitive Tempo and academic functioning in youth with Attention-Deficit/Hyperactivity Disorder (ADHD). Journal of Abnormal Child Psychology, 42(1), 91-103. doi:https://doi.org/10.1007/s10802-013-9722-3

Langberg, J., Becker, S., Dvorsky, M., \& Luebbe, A. (2014b). Are sluggish cognitive tempo and daytime sleepiness distinct constructs? Psychological Assessment, 26(2), 586-597.

Lee, S., Burns, G., Snell, J. \& McBurnett, K. (2014). Validity of the sluggish cognitive tempo symptom dimension in children: Sluggish cognitive tempo and ADHD-inattention as distinct symptom dimensions. Journal of Abnormal Child Psychology, 42(1), 7-19.

Marshall, S., Evans, S., Eiraldi, R., Becker, S., \& Power,T. (2014). Social and Academic Impairment in Youth with ADHD, Predominately Inattentive Type and Sluggish Cognitive Tempo. Journal of Abnormal Child Psychology, 42, 77-9o. doi:https://doi.org/10.1007/s10802-013-9758-4

Mcnamara, S. (200o). Stress in young people, what's new and what can we do? New York: Continuum.

Mruk, C. (1999). Self-esteem: Research, theory and practice ( $2^{\text {nd }}$ ed.). New York: Springer Publishing Company.

Salama, M. (1991). Self-esteem and parental control for children at the end of adolescence and early adulthood (in Arabic). Journal of Psychological Studies, 1(4), 679-702. 
Saleh, Z. (1992). Educational psychology (in Arabic) (14 $4^{\text {th }}$ ed.). Cairo: Arab Renaissance House.

Voinescu, B., Szentagotai, A. \& David, D. (2012). Sleep disturbance, circadian preference and symptoms of adult attention deficit hyperactivity disorder (ADHD). Journal of Neural Transmission, 119(10), 1195-1204.

Watabe, Y., Owens, J., Evans, S., \& Brandt, N. (2014). The relationship between Sluggish Cognitive Tempo and impairment in children with and without ADHD. Journal of Abnormal Child Psychology, 42(1), $105-115$.

Willcutt, E., Chhabildas, N., Kinnear, M., DeFries, J., Olson, R., Leopold, ... \& Pennington, B. (2014). The internal and external validity of sluggish cognitive tempo and its relation with DSM-IV ADHD. Journal of Abnormal Child Psychology, 42(1), 21-35. 